\title{
USE OF RECYCLED POLYPROPYLENE GRAINS AS PARTIAL REPLACEMENT OF FINE AGGREGATE IN REINFORCED CONCRETE BEAMS
}

\author{
Joseph Olawale AKINYELE ${ }^{\mathrm{a}, \mathrm{b}}$, Ramhadhan Wanjala SALIM ${ }^{\mathrm{a}}$, Gbolahan OYETI ${ }^{\mathrm{b}}$ \\ ${ }^{a}$ Department of Civil Engineering, Faculty of Engineering and the Built Environment, \\ Tshwane University of Technology, Pretoria, 0001 South Africa \\ ${ }^{b}$ Department of Civil Engineering, Federal University of Agriculture, Abeokuta, 0022 Nigeria
}

Received 28 may 2015; accepted 06 July 2015

\begin{abstract}
Waste product from polyethylene materials are non-biodegradable and they form the bulk of the materials been used today. This paper looked into how this waste product was recycled in to polypropylene grains of sizes $<4.5 \mathrm{~mm}$ and used to partially replace fine aggregate in concrete. Sieve analysis was carried out on the recycled polypropylene waste. Reinforced concrete beams (600 mm x $150 \mathrm{~mm}$ x $200 \mathrm{~mm})$ and concrete cubes $(150 \mathrm{~mm} \times 150 \mathrm{~mm}$ x $150 \mathrm{~mm}$ ) were made from the mixture of the recycled material at different percentages of $0 \%, 4 \%, 8 \%, 12 \%$ and $16 \%$. The beams were subjected to bending moment test, while the cubes were subjected to compressive strength test. Results revealed that $43.71 \%$ of polypropylene grains passed through the $4.75 \mathrm{~mm}$ sieve. The compressive strength of the $4 \%$ mixture was $16.28 \mathrm{~N} / \mathrm{mm}^{2}$ while the control was $19.07 \mathrm{~N} / \mathrm{mm}^{2}$. The bending moment test showed that the control mix has the highest value of $14.70 \mathrm{kNm}$, while the $12 \%$ and $16 \%$ has the lowest value of $8.40 \mathrm{kNm}$ each. Deflections in the polypropylene mixes were generally higher than the control. The work concluded that recycled polypropylene grains can be used as partially replacement of fine aggregate in concrete at below $4 \%$ replacement.
\end{abstract}

Keywords: polypropylene grains, polyethylene, bending moment, recycling, fine aggregate, deflection, sieve analysis.

\section{Introduction}

The abundant and availability of petrochemical products has made the use of these materials very popular all over the world. These products are used as packages in the food industry, chemical and allied industry, and in the packaging of other useful goods.

The amount of polypropylene materials from petrochemical products consumed annually has been growing steadily due to user friendly properties (low density, strength, durability and low cost) of the materials. The world's annual consumption of polymer materials has increased from around 5 million tonnes in the 1950s to nearly 100 million tonnes today (Firat et al. 2009). After usage, these materials are disposed off, and the materials are almost non-degraded in the natural environment even after a long period of exposure. This has led to poor waste disposal, especially in some developing countries of the world.

Recycling of waste materials has been encouraged in the last decade by the World Health Organisation (WHO), and other concerned organisations, especially in the protection of the environment from diseases that may results from poor hygiene.

The improper disposal of these materials by burning, has contributed to the depletion of the ozone layers over a long period of time. Safe and efficient waste disposal is one of the major activities that improve the standard of environmental condition. Kallman (2006) 
noted that in Hamburg, Germany alone, the city produces about 1.4 million tonnes, while in the United State of America, it produces 200 million tonnes of solid waste annually. A typical American generates waste on average of $2 \mathrm{~kg}$ of solid waste each day. Several researchers have looked in to the possibility of recycling all these waste products for the benefit of the environment, especially in the construction industry. Different waste materials have been reused with cement and concrete in order to reduce the negative effect of these waste products on the environment.

Fly ash is a by-product of coal fired electric generating plant. It was used to partially replace Portland cement (by up to $60 \%$ by mass). The properties of fly ash depend on the type of coal burnt. In general, siliceous fly ash is pozzolanic, while calcareous fly ash has latent hydraulic properties (U.S. Federal... 2007). Mineral admixtures are very fine-grained materials and are added to the concrete mix to improve the properties of concrete while blended cements are used as a replacement for Portland cement (Kosmatka, Panarese 1988).

Some research has also been carried out in the use of fibre reinforced polypropylene (FRP) as alternative reinforcement to steel in reinforced concrete structures. Waste from polyethylene sachets were converted to polypropylene rod by Akinyele and Olatomide $(2012 ; 2014)$. The rod was used to replace steel in reinforced concrete façade, the work also looked at the effect of high temperature on the structural properties of the concrete façade, and the results obtained from both experiments were very encouraging. Evbuomwan (2013) investigated the bending moment behaviour of normal and high performance concrete beams with Glass Fibre Reinforced Plastics (GFRP), he concluded that using GFRP in high strength concrete beams showed a good promise, but the bond aspect as well as the challenge of the low modulus of the GFRP rods needs to be addressed.

Babafemi and Boshoff (2013) also looked at the time dependent behaviour of pre-cracked polypropylene fibre reinforced concrete (PFRC) under sustained loading, the work concluded that at certain percentage, the specimen showed stable response to loading after four months. The crack formation in fibre reinforced concrete beams containing longitudinal reinforcement was also investigated by Vandewalle and Parmentier (2010), the research compared estimated crack width results from Dupont (2003) work with physical model that was developed in the research, they concluded that the Dupont calculation slightly underestimate the experimentally measured crack widths for steel fibre reinforced concrete while there was an overestimation for macro-synthetic fibre reinforced concrete.

The main aim of this study is to assess the quality of concrete produced with polypropylene waste as partial replacement of fine aggregate with a view to establishing areas where such concrete can be effectively used.

\section{Materials, specimens and test methods}

\subsection{Polypropylene Waste Material (PWM)}

The polypropylene waste material which consists of mainly, waste packaging material was collected, shredded and washed and then taken to a Polythene Recycling Plant, M/S Europlus Nig. Ltd. Sagamu, Ogun-State, Nigeria. The collected polypropylene waste material was heated in an industrial plant until the material becomes crispy and hard, this was then passed in mechanical blender and grounders which breaks it down into smaller grains. About $500 \mathrm{~g}$ of the grain sized polypropylene were sieved with a B.S. sieve of size 600 micron $-4.75 \mathrm{~mm}$ this was to determine the particle size distribution of the material. Figure 1 showed the polypropylene grain sample.

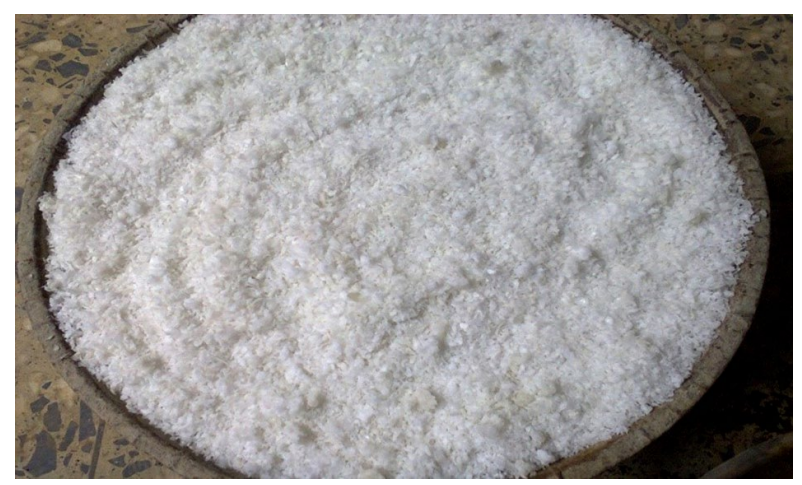

Fig. 1. Polypropylene grain sample

\subsection{Concrete batching}

The batching of the concrete was carried out by weight at a mix ratio of 1:2:4 as follows:

- For 0\% replacement; $14.28 \mathrm{~kg}$ (Cement) + 28.57 $\mathrm{kg}($ Sand $)+0 \mathrm{~kg}(\mathrm{PWM})+57.14 \mathrm{~kg}($ Gravel $)=$ $100 \mathrm{~kg}$ (Concrete).

- For 4\% replacement; $14.28 \mathrm{~kg}$ (Cement) + 27.42 $\mathrm{kg}$ (Sand) $+1.14 \mathrm{~kg}(\mathrm{PWM})+57.14 \mathrm{~kg}$ (Gravel $)=100 \mathrm{~kg}$ (Concrete) . 
- For 8\% replacement; $14.28 \mathrm{~kg}$ (Cement) + 26.28 $\mathrm{kg}($ Sand $)+2.28 \mathrm{~kg}(\mathrm{PWM})+57.14 \mathrm{~kg}(\mathrm{Gra}-$ vel $)=100 \mathrm{~kg}$ (Concrete) .

- For $12 \%$ replacement; $14.28 \mathrm{~kg}$ (Cement) + $25.14 \mathrm{~kg}$ (Sand) $+3.52 \mathrm{~kg}(\mathrm{PWM})+57.14 \mathrm{~kg}$ $($ Gravel $)=100 \mathrm{~kg}$ (Concrete).

- For 16\% replacement; $14.28 \mathrm{~kg}$ (Cement) + $23.99 \mathrm{~kg}$ (Sand) $+4.57 \mathrm{~kg}(\mathrm{PWM})+57.14 \mathrm{~kg}$ $($ Gravel $)=100 \mathrm{~kg}$ (Concrete) .

\subsection{Water-cement ratio}

For the fact that water-cement ratio influences the strength of concrete, care was taken in the selection of suitable water-cement ratios to be used in the trial mix, taking into account the nature of aggregate. Test samples were first prepared, a water-cement ratio of 0.75 was settled for because all other water ratio does not give proper mix that is required due to poor workability, this can be attributed to the nature of the polypropylene grain that is fluffy and dry, the polypropylene grains attracted some water molecules to it in order to become wet, the fluffy nature of the grains allowed more void within the concrete mix, and more water is required to fill this void hence a higher water cement ratio.

\subsection{Compressive strength test}

Compressive strength is the most important property of concrete that is used to assess the quality of concrete, (Neville, Brooks 2002), the cube samples were subjected to compressive strength test in accordance to the appropriate British Standards. The crushing machine used for the test was the Universal Testing Machine (Okhart Digital Machine, OK 600 kN, 2012 model) in the laboratory of the department of Civil Engineering, Federal University of Agriculture, Abeokuta, Nigeria. It was used to determine the crushing load. The machine applied load axially on the cube specimen at constant rate until a minimum load which corresponds to the ultimate compressive load was recorded as the failure load for that cube. The compressive strength of each cube was then calculated.

\subsection{Preparation of beam samples}

Fifteen sets of concrete beams with size $600 \mathrm{~mm} \times$ $150 \mathrm{~mm} \times 200 \mathrm{~mm}$ were produced, the beams were reinforced using 4 number $12 \mathrm{~mm}$ diameter - high yield steel bars, with two bars each at the top and bot- tom of the beams respectively, also, $6 \mathrm{~mm}$ diameter bar was used as stirrup at $150 \mathrm{~mm}$ centre to centre. First three sets of concrete beams were prepared using cement, sand and coarse aggregates which served as the control sample, while the other sets consists of cement, coarse aggregates, and a varying percentage of fine aggregate-polypropylene (i.e., at $4 \%, 8 \%, 12 \%$ and $16 \%$ ) as a partial replacement for sand. For each percentage substitution of PWM 3 beams were cast for the mix. All beams cast for these mixes were labelled $\mathrm{C} 1, \mathrm{C} 2, \mathrm{C} 3, \mathrm{C} 4$ and $\mathrm{C} 5$. The preparation of the samples was carried out in accordance to the relevant British Standards such as BS 1881 part 116 . The samples were removed from the mould after 24 hours and allowed to cure for 28 days when the concrete was expected to have attained it compressive strength.

\subsection{Bending moment, deflection and crack width determination}

The U.T.M was used to determine the failure load of the beam samples; the single point load was applied axially on the beam sample at constant rate until a maximum load which corresponds to the ultimate failure load was recorded for the beams. The deflections at the constant rates were also recorded until failure, crack width and crack length was measured at failure load and estimated crack width at failure was also determined using Eq. (1) from BS 8110 (2001), while the bending moment of the beam samples was obtained. Figure 2 showed a sample beam in the machine:

$$
w_{\max }=\frac{3 a_{c r} \varepsilon_{m}}{1+2\left(\frac{a_{c r}-c_{\min }}{h-x}\right)} .
$$

\section{Results and discussions}

\subsection{Sieve analysis results}

The results showed that $43.71 \%$ of the polypropylene grains passed through the $4.75 \mathrm{~mm}$ sieve size, $23.43 \%$ passed through the $2.36 \mathrm{~mm}$ diameter sieve size, while $0.01 \%$ passed through the 150 micrometer sieve size (Fig. 3). The coefficient of uniformity $\left(\mathrm{C}_{\mathrm{u}}\right)$ and curvature $\left(\mathrm{C}_{\mathrm{c}}\right)$ was 8.46 and 0.16 respectively; this can be classified as a well graded material, according to ASTM D2487:06. And this showed that the material can be used as partial replacement for fine aggregate in concrete since the standard size for fine aggregate in concrete is $4.75 \mathrm{~mm}$ or less. 


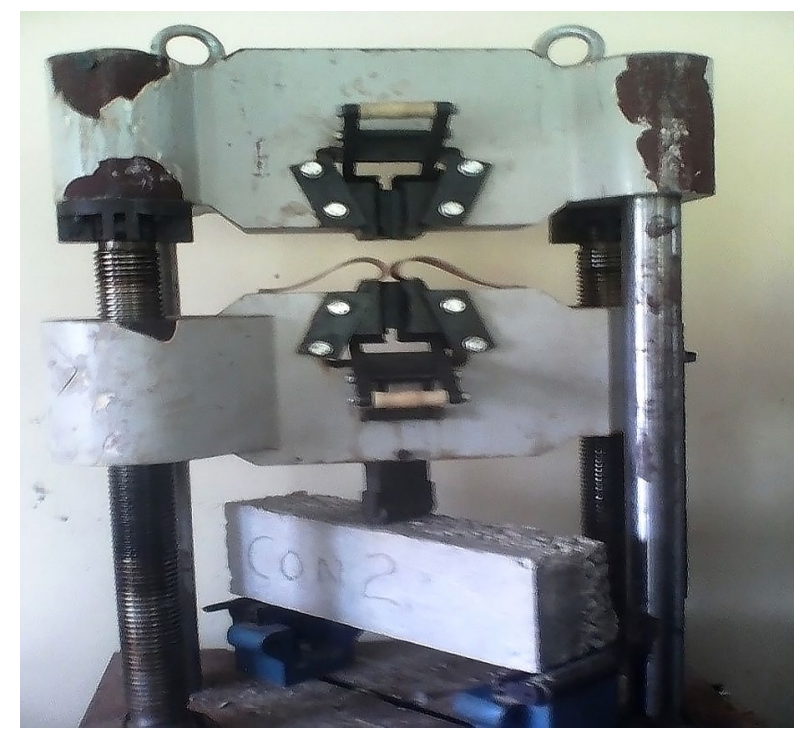

Fig. 2. Beam under load

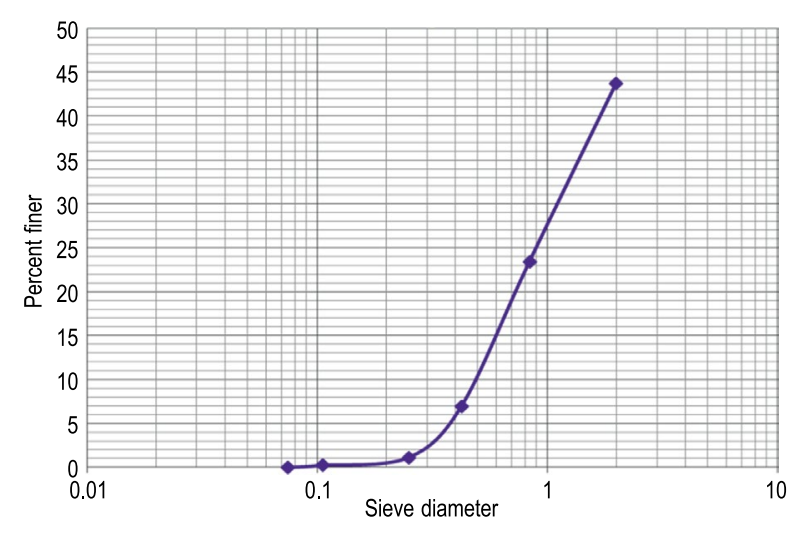

Fig. 3. Grain size distribution for polypropylene grains

\subsection{Compressive strength test result}

The mass of each cube was measured after 28 days and the compressive strength was also obtained, there was a general reduction in the compressive strength of concrete cubes as sand was been replaced with polypropylene materials, the same trend was observed in the mass of the cubes. Figure 4 showed the compressive strength result while Figure 5 showed the change in mass of the concrete cubes as polypropylene grain was added to the mix. The reduction in compressive strength with increasing in the amount of polypropylene grains can be attributed to the tiny voids created within the concrete matrix by the presence of the fluffy polypropylene grains, these voids were filled with water when the concrete was wet, and this also contributed to the high water cement ration of 0.75 that was used and the eventual low cube strength of $19.07 \mathrm{~N} /$ $\mathrm{mm}^{2}$ obtained for the control sample. After the con-

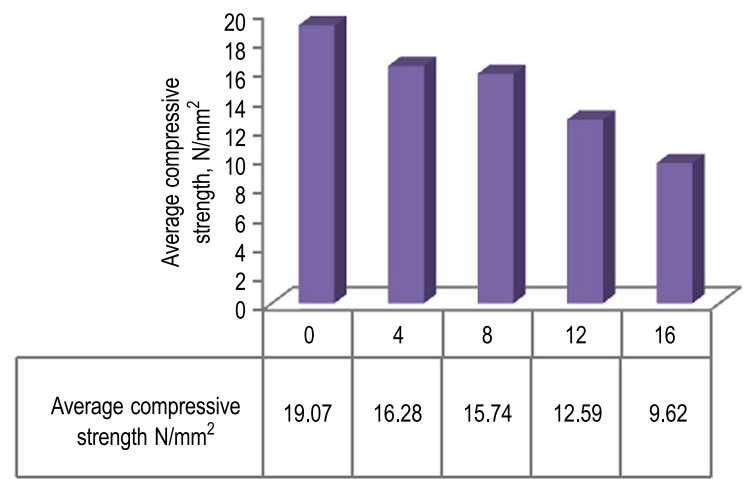

Fig. 4 . The 28 days compressive strength result

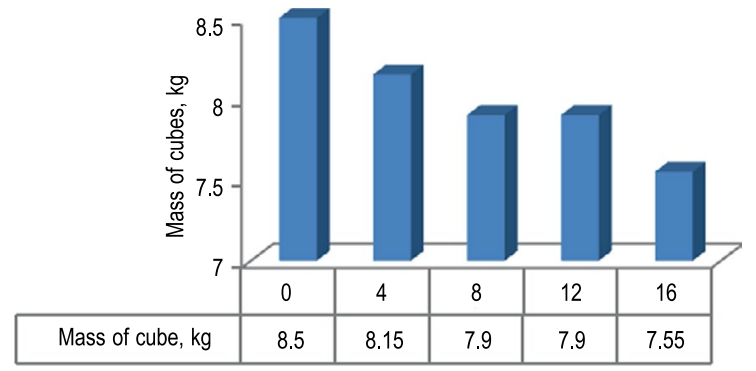

Fig. 5. Mass of concrete cubes at 28 days

crete has attained its 28 days characteristics, the tiny voids created act as weak points within the concrete matrix. The reduction in weight of concrete cubes with increase in the polypropylene grains was as a result of the voids created within the concrete matrix and the specific gravity of the polypropylene grain which is 0.73 , compared to that of river sand which is approximated to be around 2.8 . The result for the $4 \%$ replacement is very close to the $0 \%$ which is the control. These are the encouraging results for the partial replacement of fine aggregate in concrete.

\subsection{Bending moment}

When any structural concrete element is subjected to bending moment, a portion of the element is in tension while another portion will be in compression. In reinforced concrete structures, the entire tensile force is resisted by reinforcements and compression by concrete. As further load is applied to the concrete structures higher stresses are developed between the concrete matrix and the reinforcement, and cracks will start developing, after cracking of the concrete section, the structure continues to behave elastically, provided the stress in the steel is below the yield point and compressive stress in the concrete does not exceed the bond strength between the reinforcement and con- 
crete. Basically the ability of any concrete structure to provide enough resistance to the effect of external load without destabilization within the concrete section is known as it rigidity or stiffness. The results from Figure 6 showed that the beam without any polypropylene grain has a bending moment of $14.70 \mathrm{kNm}$, the $4 \%$ replacement with polypropylene grains has a moment of $13.50 \mathrm{kNm}$, the $8 \%$ replacement has $12.90 \mathrm{kNm}$ while both the $12 \%$ and $16 \%$ replacement has the same value of $8.40 \mathrm{kNm}$, it can be observed that the higher the replacement the lower the bending moment in the reinforced concrete beams. This can be attributed to the presence of the fluffy polypropylene grains in the concrete structures, the polypropylene reduced the stress developed within the concrete matrix because it could not properly mix with the concrete matrix due to it insolubility nature and low density when compared to the other materials that made up the concrete. The bond strength between the concrete and reinforcement is reduced as the replacement increases because the polypropylene grains encourage slippery contact between the surface of reinforcement and the concrete. The results between the control and $4 \%$ replacement are very close, hence partial replacement of fine aggregate with polypropylene grains at any percentage lower that $4 \%$ should be given a good consideration.

\subsection{Deflection of beams}

Deflection in beam will occur when the bending moment rigidity of the structure is exceeded, the structural member responds to increasing loads, the stiffness is maintained within the elastic limit, if the loads were remove at this stage there is the tendency for the beam structure to revert back to it pre-loading period, but whenever the elastic limit is exceeded the concrete will loss it stiffness and it will never recover it preloading stage again. The results from Figure 7 showed that the control sample has the highest stiffness, it failed at $98 \mathrm{kN}$ and the final deflection was $3 \mathrm{~mm}$, both the $4 \%$ and $8 \%$ replacements has the highest deflection of $10 \mathrm{~mm}$ but failed at $90 \mathrm{kN}$ and $86 \mathrm{kN}$ respectively, this implies that both samples were able to resist the external load for a long period, but the stress generated within the concrete matrix was very high before the final failure of the structures, this high stress is as a results of reductions in the internal bonds between the concrete particles due to the presence of the fluffy po-

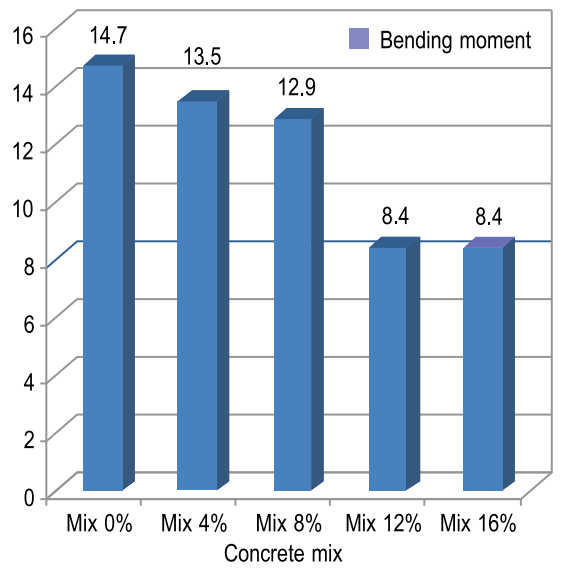

Fig. 6. Bending moment of beam samples

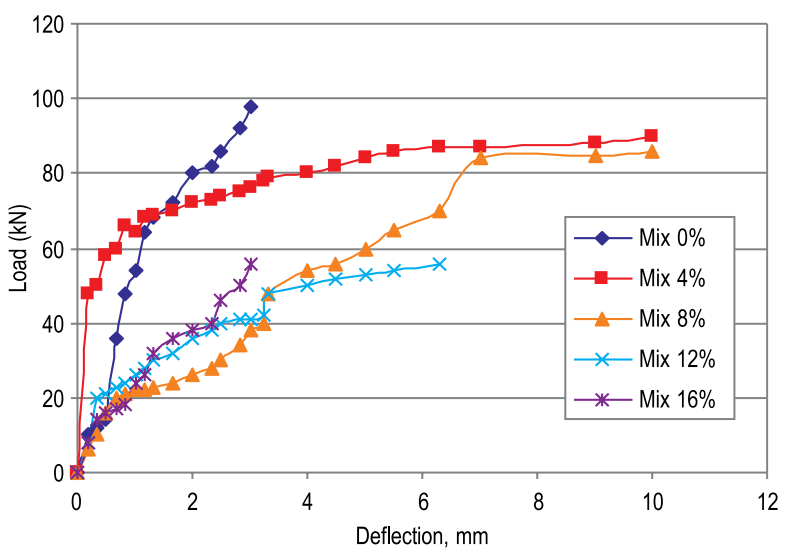

Fig. 7. Deflection of all samples

lypropylene grains, the presence of these grains increased the elastic properties of the beams, hence the very high deflection recorded in both sample. The $12 \%$ and $16 \%$ replacements both failed at $56 \mathrm{kN}$, but deflected at $6.3 \mathrm{~mm}$ and $3 \mathrm{~mm}$ respectively, this two samples could not generate high deflection because they both failed earlier than the other concrete replacements, the bond within these concrete materials was too weak to resist the impact of the external load, as a result of the excess number of polypropylene grains which also contributed to the increase in plasticity of the two beam samples. The $12 \%$ mix deflected more than the $16 \%$ mix because the stress generated within the concrete section is higher than the $16 \%$ sample, the concrete was able to hold it bond together for a longer time. The general nature of all the curves obtained in Figure 7 confirmed the fact that concrete is ductile, and it can be classified as an elastoplastic material. Such material behave in an elastic manner until the elastic limit is reached after which they behave plastically (Megson 2002). 


\subsection{Crack formation}

Members subjected to bending generally exhibit a series of distributed bending moment cracks, even at service load. These cracks are harmless and can not cause any damage to the structure unless the widths become excessive (Mosley et al. 1999). Excessively wide cracks can be unsightly and spoil the appearance of an exposed concrete surface. They can allow the ingress of moisture and accelerate corrosion of the reinforcement and durability failure. In exceptional cases; they can reduce the contribution of the concrete to the shear strength of a member (Gilbert 2001).

The crack widths for the specimen are shown in Table 1 . The results showed that the control sample has the lowest crack width of $0.59 \mathrm{~mm}$ at failure load, but the crack length was $23.67 \mathrm{~cm}$, the crack formed in this beam sample is an enhanced shear crack (Fig. 8), this is because the cracks originated from the support, as the load is increased, the cracks continue to move towards the direction of the point load, this phenomenon continued until the beam finally failed. At the point of failure, the machine was stopped from further loading and the crack width was measured using a digital veneer caliper of sensitivity up to $0.01 \mathrm{~mm}$. All the beams with polypropylene grains exhibit Bending moment crack pattern, the crack originated from the middle of the beam, and spread toward the point load, while at a point some of the cracks started moving towards the support before the failure load was attained, Figure 9 showed the crack patterns for the beam sample with polypropylene grains. The $16 \%$ replacement has the highest crack width of $7.46 \mathrm{~mm}$, followed by the $8 \%$ and $4 \%$, with crack width of $5.17 \mathrm{~mm}$ and $2.28 \mathrm{~mm}$ respectively.

The impact of the polypropylene grains can be observed in the crack width formation of all the samples with partial replacement of fine aggregate, cracks can develop in concrete due to change in temperature, deflection of structural members, and excessive loading. The effect of bond strength within the concrete matrix can reduce the development of cracks, high strength concrete generally have low or sometimes do not show any crack characteristics because of the strong bond between the concrete particles. But the presence of any external particles like the polypropylene grains tend to reduce this bonding, when such situation occurs, the development of cracks are encouraged. From the results in Table 1, the crack width increases as the percentage of polypropylene grains increases.

The estimated crack width of the control sample was lower than the experimental crack width, this can
Table 1. Crack properties of samples

\begin{tabular}{|c|c|c|c|}
\hline Specimen & $\begin{array}{c}\text { Crack length } \\
(\mathrm{cm})\end{array}$ & $\begin{array}{c}\text { Crack width } \\
(\mathrm{mm})\end{array}$ & $\begin{array}{c}\text { Estimated } \\
\text { Crack width } \\
(\mathrm{mm})\end{array}$ \\
\hline $0 \%$ & 23.67 & 0.59 & 0.21 \\
\hline $4 \%$ & 19.33 & 2.28 & 0.19 \\
\hline $8 \%$ & 25.50 & 5.17 & 0.18 \\
\hline $12 \%$ & 27.50 & 6.02 & 0.11 \\
\hline $16 \%$ & 23.67 & 7.46 & 0.11 \\
\hline
\end{tabular}

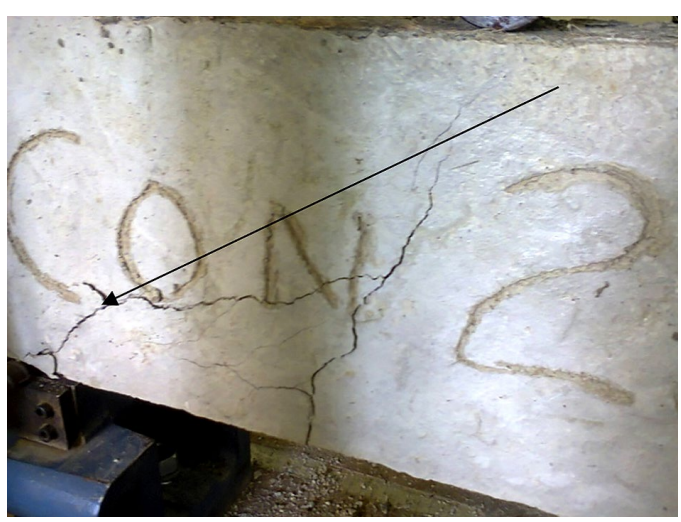

Fig. 8. Shear cracks in control beam ( $0 \%$ mix)

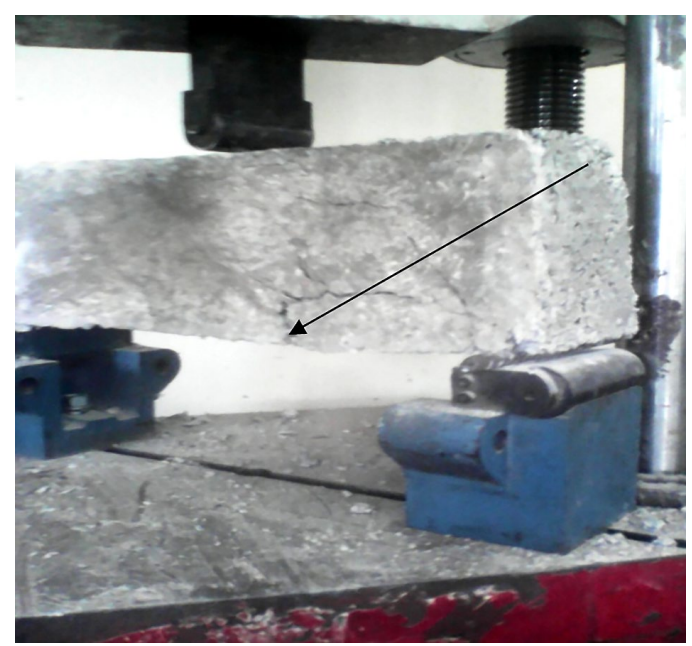

Fig. 9. Bending moment cracks in beam with polypropylene grains

be attributed to the fact that the estimated crack width equation was based on an ideal situation, although the difference between the two results are not much. But when this was compared to the samples with the polypropylene grains, the difference between estimated crack width and experimental crack width was very high, and this can be attributed to the fact that the presence of the polypropylene materials in the concrete matrix reduced the bonding strength in the reinforced concrete, since the concrete was to resist both com- 
pressive and tensile stresses, the low bonding strength allow the easy disintegration of the concrete material when continuous load was applied to the samples, hence the very high experimental crack width experienced in the concrete with polypropylene grains.

\section{Conclusions}

Various tests were carried out on concrete samples containing recycled polypropylene grains that were used in the partial replacement of fine aggregate, it can be concluded that:

1. The compressive strength of samples decreases as the content of PWM increases in the concrete.

2. The mass of samples containing PWM as a partial replacement of fine aggregate is relatively low when compared with the control.

3. The bending moment strength of the samples varies invariably at different percentage replacement of sand with polypropylene. It was noticed that the samples has higher stiffness between $0 \%$ and $4 \%$ replacements but are less flexible at other percentage.

4. The crack lengths of the samples also vary invariably with percentage replacements of sand with polypropylene. The crack width of samples increases proportionally with increasing polypropylene content.

5. The use of polypropylene grains as partial replacement of fine aggregate at $4 \%$ and below can be proposed for light weight concrete and structural members that are not exposed to excessive loading, it can also be use for rigid pavement in road construction, but the abrasive properties of the concrete can be tested in order to determine the slippery characteristic of the concrete surface when wet.

\section{References}

ASTM. D2487:06. 2006. Standard practice for classification of soils for engineering purposes (Unified Soil Classification System). ASTM Committee D18, ASTM International, USA.
Akinyele, J. O.; Olatomide, B. O. 2012. Effective utilization of waste polyethylene sachets as reinforcements in concrete façade, in $11^{\text {th }}$ AES-ATEMA International Conference on Advanced and Trends in Engineering Materials and Their Application, 6-12 August, 2012, Toronto, Canada, 351-357.

Akinyele, J. O.; Olatomide, B. O. 2014. Structural response of heated polypropylene reinforced concrete façade to loading, Acta Tehnica Corviniensis - Bulleting of Engineering 7(2): 51-56.

Babafemi, A. J.; Boshoff, W. P. 2013. Time-dependent behaviour of pre-cracked polypropylene fibre reinforced concrete under sustained loading, in Research and application in structural engineering and computation. Zingoni (Ed.). London: Taylor and Francis Group.

BS 8110. Part 1. 2001. Design of reinforced concrete structures. London: British Standard Institute.

Dupont, D. 2003. The use of steel fibres as reinforcement in structural concrete: Ph.D Thesis. Leuven: Catholic University of Leuven.

Evbuomwan, N. F. O. 2013. Bending moment behaviour of GFRP prismatic beams in composite action with concrete, in Research and application in structural engineering, mechanics and computation. Zingoni (Ed.). London: Taylor and Francis Group.

Firat, B.; Ali, G.; Olgac Kangal, M. 2009. Selective separation of virgin and post-consumer polymers (PET and PVC) by floatation method, Waste Management 29(6): 1807-1813.

Gilbert, R. I. 2001. Shrinkage, cracking and deflection - the serviceability of concrete structures, Electronic Journal of Structural Engineering 1(1): 2-14.

Kallman, M. 2006. Talking trash: the world's waste management problem. Washington: World Resource Institute.

Kosmatka, S. H.; Panarese, W. C. 1988. Design and control of concrete mixtures. Skokie: Portland Cement Association.

Megson, T. H. G. 2002. Structural and strength analysis. Oxford: Butterworth-Heinemann.

Mosley, W. H.; Bungey, J. H.; Hulse, R. 1999. Reinforced concrete design. $5^{\text {th }}$ ed. Basingstoke: Macmillan Publishers Limited.

Neville, A. M.; Brooks, J. J. 2002. Concrete technology. Essex: Longman Ltd.

Vandewalle, L.; Parmetier B. 2010. Cracking behaviour of fibre reinforced concrete beams containing longitudinal reinforcement. Advanced and trends in structural engineering, mechanics and computation. Zingoni (Ed.). London: Taylor and Francis Group.

U.S. Federal Highway Administration. 2007. Fly Ash. [online], [cited 24 January 2015]. Available from Internet: http:// www.fhwa.dot.gov/infrastructure/materialsgrp/flyash.htm

Joseph Olawale AKINYELE, Doctor and Visiting Researcher at the Tshwane University of Technology, (TUT) Pretoria, South Africa. Author of more than 25 publications. Research interests: theory of reinforced concrete behavior, analysis of structures, structural engineering materials, and the finite element method.

Rahmadhan Wanjala SALIM, Doctor, and Senior Lecturer at the Tshwane University of Technology (TUT) Pretoria, South Africa. Authored a number of papers. Research interests: analysis of structures, finite element method, theory of shells and plates, structural engineering materials, composite structures.

Gbolahan OYETI, Bachelor of Civil Engineering at the Federal University of Agriculture, Abeokuta, Nigeria. Research interests: composite structures and civil engineering materials. 